\title{
Globalización y metamorfosis metropolitana en América Latina. De la ciudad a lo urbano generalizado ${ }^{1}$
}

\author{
Carlos A. de Mattos ${ }^{2}$
}

\begin{abstract}
RESUMEN
Durante las últimas décadas del siglo pasado, bajo los efectos entrelazados, por una parte, de un nuevo sistema tecnológico articulado en torno a las tecnologías de la información y las comunicaciones y, por otra, de la aplicación de un enfoque de gobernanza basado en una amplia liberalización económica, se puso en marcha una nueva fase de modernización capitalista, la cual ha tendido a cubrir prácticamente al planeta en su conjunto. A lo largo de esta fase se produjo la progresiva y generalizada ampliación mundial del espacio de acumulación, como un rasgo constitutivo del proceso de globalización. Con ello se inició la conformación de una nueva geografía económica mundial, en la que un número creciente de grandes aglomeraciones urbanas se ubicaron como protagonistas principales; estas aglomeraciones, al irse imbricando en la dinámica global, han comenzado a vivir una verdadera metamorfosis, en la que se procesa su evolución hacia lo urbano generalizado. Frente a esta evolución, este trabajo busca precisar la dirección, el significado y el alcance de esta metamorfosis, y, en particular, caracterizar las principales particularidades con que este proceso se ha manifestado en las metrópolis latinoamericanas.
\end{abstract}

Palabras clave: Globalización, revolución informacional, metropolización expandida, metamorfosis urbana, urbano generalizado.

\begin{abstract}
During the last decades of the past century, under the intertwined effects of a new technological system articulated around technologies of information and communications in one hand, and by the implementation of a governance approach based on broad economic liberalization in the other, a new phase of capitalist modernization has been launched, which has tended to cover virtually the entire planet. Throughout this phase, there was a progressive and widespread global expansion of the area of accumulation, as a constitutive feature of the globalization process. This initiated the formation of a new global economic geography, in which a growing number of large urban agglomerations ranked as major players and these clusters, as these agglomerations became part of the global dynamic, they begun to experience a real metamorphosis, in which is possible to process their evolution towards a widespread urban. Given this evolution, this paper seeks to determine the direction, the meaning and scope of this metamorphosis, and in particular, to characterize the main features that this process has shown in Latin American cities.
\end{abstract}

Key words: Globalization, information revolution, metropolisation expanded urban metamorphosis, widespread urban.

1 Este trabajo fue elaborado como contribución a una
investigación sobre competitividad urbana referida
a Santiago de Chile, coordinada por el autor, en el
marco del Proyecto FONDECYT $N^{\circ} 1085257$, en
ejecución durante el período 2008-2010. Artículo recibido el 24 de marzo de 2010 y aceptado el 1 de octubre de 2010.

2 Instituto de Estudios Urbanos y Territoriales, Pontificia Universidad Católica de Chile (Chile). E-mail: cdmattos@uc.cl 
Durante las últimas décadas del siglo pasado, bajo los efectos entrelazados, por una parte, de un nuevo sistema tecnológico articulado en torno a las tecnologías de la información y las comunicaciones (TIC) y, por otra, de la aplicación de un enfoque de gobernanza basado en una amplia y generalizada liberalización económica, cobró impulso una dinámica económica substancialmente diferente a la que se había impuesto luego de la gran crisis de 1929. Con ello, se puso en marcha un proceso que por la profundidad y el alcance de las transformaciones que produjo, puede considerarse, stricto sensu, como una nueva fase de modernización capitalista.

Con el avance de la reestructuración económica y de la informacionalización, procesos medulares de esta fase modernizadora, se originó una progresiva y generalizada ampliación geográfica de un espacio de acumulación, que tiende a adquirir cobertura mundial como expresión básica de la globalización. Los cambios en las condiciones para la competitividad que ocurrieron con esta expansión del espacio de acumulación, indujo a un número creciente de empresas a adoptar nuevas modalidades organizativas, capaces de permitir mejorar su presencia competitiva en diversos lugares del mismo. Como parte central de las estrategias aplicadas para aumentar su competitividad, numerosas empresas comenzaron a dispersar una cantidad cada día mayor de componentes de sus procesos productivos por diversos puntos de ese espacio de acumulación, los cuales tendieron a localizarse principalmente en grandes aglomeraciones urbanas de los países escogidos; con ello, se produjeron cambios substanciales en la geografía económica mundial, entre los que jugó un papel central la recuperación de la importancia de numerosas grandes aglomeraciones urbanas. A medida que estas aglomeraciones se fueron imbricando en la dinámica productiva globalizada, una verdadera metamorfosis comenzó a afectar tanto a su organización y funcionamiento, como a su morfología y apariencia.

Con el propósito de identificar y caracterizar la dirección y significado de esta metamorfosis, este trabajo analiza la interacción entre reestructuración económica y transformación urbana, considerando algunas de las particularidades con las que este proceso se ha manifestado en las principales metrópolis latinoamericanas. Este análisis busca aportar elementos de juicio para mostrar cómo los cambios que han tenido mayor incidencia en esta evolución lo hicieron siguiendo algunas tendencias genéricas globales, cuya irrupción y/o fortalecimiento solamente puede explicarse como consecuencia de las transformaciones constitutivas de esta fase de modernización capitalista; y que estas tendencias están marcando su presencia en todas las ciudades que se han involucrado estructuralmente en la nueva dinámica económica global, aun cuando pueden asumir modalidades y alcances específicos en cada ciudad.

\section{Nuevas tecnologías de la información, liberalización económica y dependencia del capital}

Para explicar la dirección seguida por este nuevo proceso modernizador es necesario revisar las motivaciones, los fundamentos y los principales efectos de las respuestas, tanto públicas como privadas, adoptadas al buscar una salida al agotamiento del modelo de acumulación y crecimiento keynesiano-fordista que había logrado imponerse a partir de la Gran Depresión, con diversas especificidades nacionales, en buena parte del mundo occidental, y en América Latina, en particular. En la estructuración de esas respuestas incidieron de manera decisiva dos fenómenos específicos, que se constituyeron en los ejes articuladores de una nueva dinámica económica que rápidamente se propagó por el mundo entero: uno que se desarrolló en el plano científico-técnico y el otro en el del discurso teórico-ideológico.

En el plano tecnológico, el cambio fundamental se provocó con la generación y la difusión de las TIC que, desde las últimas décadas del siglo pasado, aportaron un medio cualitativamente distinto para el establecimiento de nuevas formas de conectividad y de movilidad, y mucho más potente y eficaz para el despliegue territorial por todo el planeta de una nueva arquitectura financiera y productiva. Desde el punto de vista teórico-ideológico, una nueva matriz de poder social, que se había afirmado con la 
propia evolución fordista, se mostró proclive a impulsar un esfuerzo sistemático de liberalización económica, cuya materialización se tradujo en una progresiva desfronterización de los territorios nacionales y en la constitución de un espacio supranacional de acumulación.

Sin duda, el generalizado fracaso de los intentos por planificar centralizada y normativamente el "desarrollo económico y social", que habían tenido su apogeo en la segunda postguerra, tanto en los países capitalistas como en aquellos que habían escogido un destino alternativo, fue uno de los factores que también contribuyó a este regreso al liberalismo económico, ahora en su versión conocida como neoliberalismo. Así, después del auge alcanzado por los alegatos sobre la necesidad y la posibilidad de una intervención exógena al mercado a fin de regular el crecimiento capitalista, se produjo un retorno a la certeza de que solamente era posible encontrar una salida a la crisis con el pleno restablecimiento del juego de las fuerzas del mercado. En lo medular, esto significó que la dinámica que entonces comenzó a desplegarse globalmente se vertebró en torno a dos creencias básicas que, por la propia profundidad de la crisis que entonces enfrentaba el modelo anterior, fueron aceptadas con escasa resistencia: en primer lugar, que en el marco de los fundamentos teórico-ideológicos del "modelo" que se había estructurado e impuesto luego de la Gran Depresión, y que había tenido un desempeño relativamente exitoso en los países centrales durante la segunda postguerra, ya no era posible encontrar respuestas viables y eficaces para una plena reactivación de la economía mundial; y, en segundo lugar, que estas respuestas -así como la reestructuración que ellas deberían promover- debían estar orientadas a restablecer las condiciones que asegurasen el funcionamiento "natural" de una economía capitalista, lo que significaba ante todo devolver al mercado su función de mecanismo básico de regulación económica y al capital privado su papel de protagonista efectivo de la dinámica de acumulación y crecimiento.

Desde fines de la década de los años setenta, con la articulación y retroalimentación de estos impulsos se hizo evidente la necesidad de introducir nuevos arreglos institucionales capaces de lograr un mejor despliegue global de la dinámica económica que entonces comenzó a perfilarse. En este sentido, el nuevo discurso suponía que los arreglos institucionales establecidos en la fase anterior obstaculizaban la emergencia y la propagación de una dinámica económica que permitiese la plena utilización de las potencialidades que ofrecían las innovaciones aportadas por la revolución científico-técnica informacional en una economía de mercado y que, por tanto, era necesario adoptar las medidas que permitiesen corregir esa situación. Por otra parte, en esta dirección, el mismo avance de la revolución tecnológica informacional puso en evidencia la necesidad de una institucionalidad funcional a su mejor despliegue y utilización. En esas circunstancias se aceptó que, como afirma Carlota Pérez (2004: 30), cada revolución tecnológica, "se acompaña de lineamientos de 'óptima práctica', bajo la forma de un paradigma tecno-económico, capaz de romper con los hábitos existentes en tecnología, economía, gerencia e instituciones sociales".

Si se analiza lo ocurrido en estos años, se puede comprobar que a medida que los postulados del discurso neoliberal en pos de esa "óptima práctica" fueron ganando aceptación, sus indicaciones empezaron a ser aplicadas en distintas partes del mundo, obviamente con diferencias de énfasis e intensidad entre un lugar y otro, produciendo importantes cambios que modificaron radicalmente el escenario económico global. En particular, ganó consenso rápidamente la propuesta sobre la necesidad de "[...] instaurar en el mayor número posible de países [...] un terreno de maniobra que permitiese el libre despliegue de las estrategias de las firmas, sea para ensanchar el mercado, sea para minimizar los costos unitarios, sea para los dos a la vez" (Michalet, 2007: 107-108); lo cual tuvo como consecuencia fundamental la conformación de un espacio de acumulación de cobertura mundial que, desde ese momento, condiciona la dinámica esencial de la globalización. De esta manera, por decisión política, se establecieron las condiciones que hicieron posible la generalización de las principales tendencias constitutivas de un "nuevo modelo" que, en lo esencial, acompañaron la progresión de la globalización. 
$\mathrm{Y}$, con ello, se profundizaron los procesos que han sido caracterizados como de "desnacionalización institucional parcial en el interior del Estado y de cada economía nacional", que llevaron a "la formación de un orden institucional intermediario que se ubica solo parcialmente dentro del sistema interestatal y que, en realidad, está transformándose en un ámbito institucional paralelo donde se manejen las operaciones transfronterizas" (Sassen, 2007: 57). Estos cambios hicieron posible el despliegue generalizado por encima de las debilitadas fronteras nacionales de una infinidad de circuitos globalizados, entre los cuales para este análisis se destacan los de carácter financiero, productivo $y$, en particular, todos los relacionados con el consumo.

En este escenario, desde que se generalizaron las políticas destinadas a favorecer el despliegue transnacional de un conjunto de circuitos o firmas globales, entre los que los financieros fueron especialmente beneficiados, se impuso un aumento progresivo, y hasta ahora irreversible, de la autonomía de los flujos con respecto a los lugares, así como también con respecto a las indicaciones gubernamentales. Este cambio obligó a que los lugares (países, regiones, ciudades), como condición necesaria para poder mantener o aumentar sus niveles de acumulación y crecimiento, se hayan tenido que inclinar por competir entre sí por IED.

Así, bajo el impulso de múltiples circuitos globalizados fue que se propagaron e impusieron a escala global las innovaciones congénitas a esta fase de modernización capitalista, lo cual incidió en una progresiva profundización de la dependencia estructural de las respectivas sociedades nacionales con respecto al capital (Przeworski, 1990), lo cual tiene entre sus consecuencias fundamentales: i) que en estas sociedades la posibilidad de realizar una mayor acumulación y de aumentar la tasa de crecimiento está cada vez más rígidamente condicionada por la vigencia plena de reglas del juego capitalistas; ii) que con la formación y expansión de un espacio capitalista de acumulación de cobertura planetaria, las perspectivas de crecimiento en un determinado lugar están cada día más estrictamente regidas por las condiciones que ese lugar pueda ofrecer para la valorización privada del capital; y iii) que, en consecuencia, en las sociedades en las que esto tiene vigencia, se redujo cada vez más aún la factibilidad de promover objetivos sociales de interés general ( $y$, en especial, de interés para los más desfavorecidos), si esos objetivos no son compatibles con los de los propietarios y/o administradores del capital.

Con la culminación de estos procesos, quedaron sentadas las bases para la afirmación de los ejes estructurantes y las tendencias constitutivas de esta nueva fase de modernización capitalista, en la que se agudizaron las diferencias entre la globalización y las modalidades precedentes de internacionalización, estableciendo así las condiciones para la materialización de una nueva forma histórica particular del capitalismo (Held \& McGrew, 2003).

\section{Nueva arquitectura productiva y reconfiguración geográfica global}

Al generalizarse durante las últimas décadas del siglo pasado la pérdida de productividad y de competitividad de la gran empresa verticalmente integrada, que se había situado como núcleo básico del fordismo, tanto gobiernos como empresas se vieron obligados a buscar alternativas apropiadas para enfrentar los cambios en las condiciones para competir en un espacio supranacional. En ese contexto, numerosas empresas optaron por una estrategia que contempló su paulatina desintegración vertical, para lo que recurrieron a la externalización, tercerización y subcontratación de un número creciente de subprocesos productivos. Con ello se materializó una progresiva descomposición internacional de los procesos productivos (Mouhoud, 2006: 25), que condujo al establecimiento de nuevas formas de articulación multinacional, fundamentalmente por la vía de la organización productiva en cadenas organizadas globalmente. Como señaló Gereffi (1999), con la continua multiplicación del número de cadenas globales (global commodity chains) de diversa naturaleza, ha resultado que "en el capitalismo global, la actividad económica no es solamente internacional en su alcance, sino que también es global en organización" (Gereffi, 1999: 1). 
En base a esta organización, a medida que las fronteras nacionales se fueron haciendo más permeables, un número creciente de redes globales se desplegó por distintas partes del mundo, involucrando tanto a las de carácter financiero y productivo, como a las relacionadas con el consumo. En esta evolución, los componentes de cada cadena de valor (diseño, producción, marketing, comercializacion) pudieron ser deslocalizados hacia múltiples lugares de la nueva geografía, donde se materializaron en diversos tipos de islotes productivos, aun cuando con una dispersión y cobertura geográfica desigual, donde los grandes beneficiados fueron los países más desarrollados; en ese proceso, los países latinoamericanos se han ido articulando de manera desigual $y$, en general, insatisfactoria (Kosakoff y López, 2008).

En torno a estas cadenas y/o redes globales, se inició la configuración de una nueva arquitectura financiera y productiva, cuya expansión y dispersión geográfica desembocó en una configuración en nodos y redes (hubs \& networks), que se constituyó en una estructura básica con capacidad para sustentar el despliegue y reescalamiento capitalista que se impuso en esta fase; en ella, los lugares en los que se produjo el mayor entrecruzamiento de esas redes, pasaron a constituirse en nodos básicos de una geografía que tiende a abarcar a la totalidad del planeta. Desde el punto de vista económico, la organización resultante corresponde a lo que Veltz (1996) caracterizó como una "economía de archipiélago".

Fue así como la organización en red permitió la expansión a escala global de un número creciente de empresas, multiplicando e intensificando un amplio conjunto de flujos de diversa naturaleza (capital, comunicaciones, información, mercancías, personas, cultura, etc.) que, desde entonces, se despliegan prácticamente por todos los rincones del planeta, favorecidos por los nuevos medios y posibilidades en cuanto a movilidad y comunicaciones. Bajo esta dinámica, una cantidad cada día mayor de firmas globales deslocalizó y relocalizó partes diferenciadas de sus cadenas de valor en múltiples lugares estratégicamente escogidos en el espacio global.
A medida que múltiples circuitos o redes fueron "pisando tierra" ${ }^{3}$ en los diversos ámbitos nacionales escogidos, también fue tomando impulso la transición desde una organización territorial en áreas, que se había constituido en un rasgo característico de la fase anterior, hacia otra configurada como un territorio de redes, a la vez discontinuo y estratificado, producto del entrecruzamiento en determinados lugares de un cúmulo de redes de variada naturaleza (Veltz, 1996: 61). Esta transición significó la sustitución de una organización en la que predominaban las relaciones verticales entre los centros y sus áreas de influencia, hacia otra en la que se impusieron las relaciones horizontales entre un conjunto interconectado de nodos con muy diversa ubicación,

La evolución que se derivó de estos cambios marcó el progresivo reemplazo de una organización territorial en la que las relaciones centro-periferia caracterizaban la dinámica dominante, por una trama mucho más enmarañada, producto de relaciones complejas y asimétricas entre el espacio de los flujos y el espacio de los lugares. La anterior organización, de la que el modelo de los lugares centrales de Christaller había constituido por mucho tiempo la representación más aceptada -y de la que se había derivado un conjunto de propiedades en cuanto a la difusión territorial vertical de corta y media distancia- empezó a ser suplantada por otra en que "la economía está estructurada mucho más fuertemente por la red primaria metropolitana que por las relaciones verticales con las zonas o las metrópolis secundarias" (Veltz, 1996: 65).

La organización que se ha venido consolidando desde entonces tiene la peculiaridad de que, en lo esencial, en su nivel superior, privilegia la conectividad entre filiales de redes localizadas en diversos ámbitos nacionales, donde los flujos respectivos "[...] surcan los territorios y conectan a distancia a sus actores, debilitando los vínculos tradicionales de cohesión interna, basados en la

3 Expresión utilizada por Saskia Sassen (2007) para hacer referencia a la materialización de los circuitos virtuales en las ciudades en las que localizan algunas de sus actividades. 
proximidad física" (Dematteis, 2002: 170). Esto, por cuanto, como destaca Sassen (2007: 287) cada red "no busca la conexión con su entorno, sino el acceso a una geografía transfronteriza conformada por múltiples lugares especializados concretos"; por lo tanto, la operación estratégica de cada una de estas redes "no se refiere a su entorno inmediato, sino a una geografía estratégica compuesta por múltiples nodos, lo que se transforma en su contexto principal". Lo que, a su vez, implica que al modificarse las modalidades imperantes de difusión socioterritorial del crecimiento, comenzó a producirse un paulatino debilitamiento de la cohesión social por proximidad física, lo cual puede considerarse como uno de los rasgos más relevantes entre los que diferencian a la organización territorial emergente con aquella que había sido analizada por Christaller.

Esta geografía transfronteriza comenzó a afirmarse cuando un conjunto de empresas transnacionales (ETN) en proceso de reestructuración, mostró una marcada preferencia por dispersar sus nodos o filiales hacia un conjunto de ciudades estratégicamente ubicadas en el espacio mundial de acumulación, que consideraron que estaban en condiciones de ofrecerles la dotación de factores (externalidades, infraestructuras y servicios, recursos humanos calificados y diversificados, potencial innovador, etc.) que ellas requerían para materializar su despliegue. Desde el momento en que empezó a concretarse la localización de un número creciente de nodos o filiales de estas empresas en las urbes seleccionadas, estas pasaron a constituirse en los lugares en los que se desarrollaban las principales funciones de articulación de la respectiva base económica nacional con un número cada vez más elevado de circuitos globales. De esta manera, estas ciudades empezaron a formar parte, con desigual presencia e intensidad, de una red global de ciudades (world city network) (Taylor, 2004), que ha tendido a abarcar al planeta en su totalidad, como infraestructura básica para la operación de las cadenas globales. De esta tendencia ha resultado que, como afirman Moura y Firkowski (2007: 127), "en su base geográfica, un mosaico o archipiélago constituyen una de las principales redes estructurales de la nueva economía global, funcionando como plataformas territoriales a partir de las cuales grupos concentrados o redes de empresas disputan los mercados globales".

En este contexto, las urbes que han logrado formar parte de esa red global se han constituido en lugares de entrecruzamiento de flujos vertebrados por esas cadenas globales, lugares que presentan su mayor densidad en las grandes aglomeraciones del hemisferio Norte; a esa red, también se han ido incorporando, en un rango jerárquico de menor relevancia, diversas urbes de gran dimensión poblacional y territorial del resto del mundo, muchas de las cuales son consideradas principalmente como oferentes de fuerza de trabajo a bajo costo y/o como potenciales mercados para el consumo de productos globales. La importancia del papel que cada uno de estos componentes urbanos de la red, aumenta o disminuye en función de la forma que los países respectivos logran imbricarse en los circuitos globales dominantes. De ello resulta que como afirma Brenner (2003) "[...] estas regiones urbanas están ordenadas jerárquicamente a una escala global de acuerdo a sus modos de integración específicos a escala mundial". como parte de una nueva geografía global, en la que uno de sus aspectos claves es que las "unidades geográficas fundamentales" de la "nueva configuración emergente del capitalismo mundial" son "las ciudades, o más precisamente, las regiones urbanizadas a gran escala [...]" (Brenner, 2003: 8).

En ese contexto, importa tener en cuenta que las distintas áreas urbanas que han pasado a formar parte de esa red mundial de ciudades no tienen igual capacidad de atracción con respecto a los flujos, en especial a los de inversión extranjera directa (IED); esto resulta de las desiguales condiciones que cada una de ellas puede ofrecer para la valorización de los capitales en movimiento, los cuales gozan de una creciente autonomía para escoger los lugares en los que se van a localizar. Si esto es así, ¿hacia dónde se ha dirigido y pisado tierra ese flujo de capitales? A este respecto, la evidencia empírica disponible muestra que desde que las fronteras nacionales continúan existiendo, no obstante su creciente porosidad, los capitales móviles seleccionan ante todo un destino nacional para su localización, por cuanto, como indica Veltz, "[...] un gran número de condicionamientos y de datos que guían las decisio- 
nes de localización de las empresas y de los individuos (la fiscalidad, la legislación del trabajo, etc.) siguen siendo nacionales. Las encuestas muestran [...] que las grandes firmas mundiales eligen primero el país, luego la región de implantación [...]" (Veltz, 2002: 126). Por lo tanto, continúa siendo a escala nacional donde se establecen los factores básicos que condicionan la atractividad y/o competitividad de un territorio. $Y$ esto significa que, dada la desigual atractividad existente entre distintos países, los flujos respectivos se han encauzado principalmente hacia los países en los que los potenciales inversores han percibido mejores condiciones para valorizar sus capitales, lo cual es evaluado en función de un diversificado conjunto de factores, como los que habitualmente consideran los estudios sobre riesgo-soberano y sobre competitividad. Sobre esta base, como lo indica la información disponible al respecto, los capitales móviles se han dirigido preferente y mayoritariamente hacia los países de mayor desarrollo relativo, que han sido invariablemente los mejor calificados en las múltiples evaluaciones que miden aspectos relacionados directa o indirectamente con la atractividad territorial.

La evidencia empírica también muestra que, una vez decidido un destino nacional, los capitales móviles se orientan mayoritariamente hacia alguna de las principales áreas urbanas del país escogido, en el entendido de que ese es el lugar que en ese ámbito nacional ofrece las mejores condiciones para su valorización, en virtud de su mejor dotación relativa en cuanto a los factores requeridos por los componentes de las cadenas de valor de las respectivas ETN. En esta situación, las ciudades interesadas en atraer IED buscan mejorar, en la medida de sus posibilidades, las condiciones para una mejor valorización del capital. De hecho, en esto radica el fundamento básico de las estrategias de competitividad, que se han ubicado como uno de los aspectos centrales de la gestión urbana actual.

La desigual atractividad existente entre las distintas áreas urbanas que forman parte de la red global de ciudades ha sido comprobada y medida por diversos estudios e investigaciones, cuyos resultados han suministrado importantes elementos de juicio para identificar y analizar la actual conformación jerárquica de esta red y para, a partir de allí, establecer las diferencias existentes entre todas esas áreas urbanas y, en particular, entre las grandes urbes latinoamericanas, lo cual, a su vez, permite observar la ubicación y el papel que hoy día tienen los países y las ciudades de América Latina en la dinámica globalizada.

En este sentido, el Global and World Cities Group and Network (GaWC), en uno de los primeros estudios comprensivos realizados en esta dirección, evaluó la importancia relativa de las principales ciudades del mundo en función de la capacidad de cada una de ellas para suministrar los principales servicios a la producción requeridos por las ETN que se desplegaban por todo el mundo, considerando que este era un factor determinante para elegir la localización de sus filiales. Este estudio se basó en la consideración de que las "ciudades mundiales" son "[...] 'sitios de producción post-industrial', donde las innovaciones en servicios corporativos y financieros han sido parte integral de la reciente reestructuración de la economía mundial ahora ampliamente conocida como globalización" (Beaverstock, Smith y Taylor, 1999).

Con este fundamento, esta investigación relevó la capacidad de cada una de las ciudades consideradas en cuanto a su capacidad para prestar servicios de contabilidad (incluyendo auditoría), de publicidad, financieros y bancarios y jurídicos y legales. Como resultado, fueron identificadas 55 ciudades que fueron consideradas como mundiales, las que fueron clasificadas jerárquicamente en tres grupos (alfa, beta y gama) y 67 que mostraban evidencia de que se encontraban en su proceso de formación como ciudades mundiales. Cinco ciudades latinoamericanas (Ciudad de México y São Paulo en el grupo de las ciudades beta y Caracas, Santiago y Buenos Aires en el gama) fueron consideradas como parte del conjunto de las ciudades mundiales, en tanto que se concluyó que otras seis (Río de Janeiro, Bogotá, Lima, Montevideo, Brasilia y Tijuana) ya presentaban alguna evidencia de su evolución en esa dirección. En lo fundamental, esta investigación permitió comprobar que un número importante de las principales áreas urbanas latinoamericanas se encontraban en proceso de articulación a la 
dinámica de la globalización, pero con una muy desigual distribución jerárquica, Por otra parte, la información considerada indicó que la totalidad de las urbes que se situaron en el primer nivel de la misma, correspondían a países desarrollados del hemisferio Norte, como Estados Unidos (Nueva York, Chicago y Los Ángeles), Europa (Londres, París, Frankfurt y Milán) y Asia Pacífico (Tokio, Hong Kong y Singapur); y que en la red, en su conjunto, las ciudades latinoamericanas desempeñan un papel secundario.

En la misma dirección, Master Card impulsó un programa de investigación con el objetivo de "identificar y clasificar las ciudades más influyentes que conducen la economía global", la cual se sustentó en el criterio de que "las ciudades globales desempeñan funciones críticas conectando mercados y comercio a través del mundo" y que "la comprensión de la dinámica de crecimiento y la conectividad de esas ciudades es crítica para el éxito en los negocios". Con este fundamento, en la versión correspondiente al año 2008 la investigación analizó la situación de 75 ciudades, para lo cual consideró los siguientes factores: sistema legal y político, estabilidad económica, facilidad para hacer negocios, flujo financiero, centro de negocios, creación de conocimiento y flujo de información, y por último, habitabilidad. (Master Card, 2008). Los resultados de este estudio, mostraron que la ciudades que se ubicaban en las posiciones más destacadas de la clasificación eran las mismas que las que habían sido identificadas así en el estudio del GaWC, con la única diferencia de que en lugar de Milán, entre las 10 primeras aparece Amsterdam. En cuanto a las ciudades latinoamericanas, y 7 de ellas lograron situarse entre las 75 ciudades consideradas como las más influyentes de la economía mundial, aun cuando solamente el tercio final de la tabla: Santiago de Chile (en el lugar 53), Ciudad de México (54), São Paulo (56), Bogotá (62), Buenos Aires (63), Río de Janeiro (65) y Caracas (75).

De hecho, más allá de que los fundamentos teóricos y los criterios utilizados por estos estudios que, como es obvio, se derivan de una concreta teoría del crecimiento, puedan ser objeto de discusión y, aun, de rechazo, ellos brindan una imagen de la real configuración de la red mundial de ciudades en un mundo globalizado. En esa dirección, estos estudios muestran que en esta red, donde las posiciones más importantes son ocupadas exclusivamente por ciudades de los países desarrollados del hemisferio Norte, ubicados en América del Norte, Europa y Asia Pacífico, persisten grandes desigualdades entre sus distintos componentes. En lo esencial, puede afirmarse que esta organización jerárquica continúa manteniendo una distribución que en sus aspectos fundamentales no presenta grandes cambios con respecto a la división internacional del trabajo que existía al final de la fase keynesiano-fordista. En este cuadro, desde el punto de vista de los factores priorizados por estas investigaciones, las principales áreas urbanas latinoamericanas ocupan un lugar secundario en la red mundial de ciudades y muestran una adscripción marginal a la dinámica de la globalización, aun cuando algunas de ellas han realizado avances importantes en esa dirección durante las últimas décadas. Por otra parte, estos estudios también indican que el lugar que ocupan estas ciudades en el ranking final, está claramente correlacionado con la posición de los países respectivos en evaluaciones como las de globalización, riesgo-país y competitividad.

\section{Dinámica económica global y metamorfosis urbana}

\section{Metamorfosis, identidad, distintividad}

¿Cuáles son los cambios más importantes que se han observado en las áreas urbanas afectadas por la dinámica de la globalización?; ¿se han comprobado cambios que sean comunes a todas ellas? A este respecto, este trabajo busca aportar elementos de juicio en favor de la tesis de que las grandes aglomeraciones urbanas que se adscribieron a la dinámica de la globalización, al hacerlo comenzaron a padecer una metamorfosis que, bajo el impacto de ciertas tendencias que pueden considerarse como congénitas a esta fase de modernización capitalista, modificaron cualitativamente su organización, funcionamiento, morfología y apariencia. Con ello empezó a producirse en ellas la desaparición o el debilitamiento de algunos de los rasgos o atributos genéricos de la forma urbana de la 
ciudad industrial, así como también el fortalecimiento de otros entonces ya perceptibles y la irrupción de algunas tendencias y/o fenómenos nuevos. Con estas mutaciones, cada una de estas áreas ha evolucionado hacia un nuevo patrón de urbanización o forma urbana, que se ha ido imponiendo, más allá de la especificidad y/o identidad de cada una de esas aglomeraciones.

De hecho, estos procesos resultan equiparables a los que, si bien con menor rapidez y cobertura geográfica, marcaron la evolución que llevó a la formación del patrón de urbanización de lo que fue denominado como "ciudad industrial", que se impuso en diversos países bajo el avance del proceso de industrialización. Es en este sentido, que Indovina (1990: 49), al analizar la transición desde la ciudad industrial hacia la "ciudad difusa", afirma que "el punto de partida es la constatación de que han sobrevenido importantes transformaciones del fenómeno del asentamiento humano y que es preciso interpretar tales transformaciones precisamente porque no se presentan como una especie de prolongación de la fenomenología precedente, sino porque lo hacen casi como una mutación de estado". Desde esta perspectiva, se llega a la conclusión de que lo que ha provocado la actual metamorfosis urbana ha sido justamente una "mutación de estado", la cual está marcada por la convergencia hacia una nueva forma urbana, cualitativamente distinta a la que la había precedido.

Sin embargo, también cabe reconocer que en la actual metamorfosis cada una de las áreas urbanas afectadas conserva $-y$, aún, en ciertos casos, acentúa- algunos de los rasgos o atributos inherentes a lo que podría calificarse como su identidad (y/o su idiosincrasia), más allá del hecho de que, bajo los efectos de la globalización, muchos de ellos tiendan a desdibujarse y a atenuar su importancia. En esa evolución, si bien cada una de las áreas urbanas afectadas puede preservar algunas de aquellas cualidades y/o rasgos que a lo largo de su historia fueron afirmando sus específicas señas de identidad, ahora ellas también son objeto de diversas mutaciones bajo el impacto de unas tendencias constitutivas de la actual modernización. Como ya se ha señalado, esta "mutación de estado" no es contradictoria con la persistencia de aquellas señas de identidad que hacen de cada ciudad una conformación y, sobre todo, una experiencia única e irrepetible.

Por otra parte, algunos de los activos específicos ( $y$, por lo tanto, intransferibles) de una ciudad -por lo general relacionados con su entorno natural, su peculiar tipo de vida urbana, su cultura, su música, su arquitectura, sus equipamientos para la vida social, etc.- suelen ser evaluados como parte substancial de sus ventajas competitivas; es por ello justamente que por lo general las estrategias orientadas a mejorar la competitividad de estas urbes tienden a ubicar como uno de sus objetivos prioritarios el fortalecimiento, la visibilización y/o la exaltación de algunas de estas cualidades identitarias. Al respecto, importa tener presente que, como sostienen Markusen \& Schrock (2006: 1303), las ciudades "[...] están comprometidas en una lucha por distinguirse unas de otras vis-à-vis tanto el mundo externo como sus propios habitantes". En esa búsqueda de "distintividad", muchas administraciones urbanas han otorgado especial importancia a las políticas y proyectos orientados a fortalecer o a generar algún elemento o atributo que permita individualizar a esa área urbana entre las que están en competencia.

Por lo tanto, sostener que la actual revolución urbana está conduciendo a una nueva forma urbana, en ningún caso implica asumir que ello pueda llevar a la formación de ciudades en las que desaparecerían las señas de identidad que las han distinguido y las seguirán distinguiendo entre sí. Esto es, tal como ocurrió en la transición hacia la ciudad industrial en el pasado, la aparición y presencia de los cambios que habrán de caracterizar a la forma de la configuración urbana postindustrial, no resulta incompatible con la persistencia y/o reafirmación de muchos de los activos específicos que han caracterizado hasta ahora por lo menos a partes de las mismas.

\section{Movilidad, descomposición productiva, nueva economía urbana}

¿Qué efectos tuvo el despliegue de esta nueva organización productiva en las respectivas economías urbanas? Como ya se mencionó, con la reestructuración iniciada 
en las últimas décadas de siglo pasado, múltiples empresas procedieron a descomponer internacionalmente sus procesos productivos, lo que se tradujo en que un número significativo de sus filiales o subprocesos externalizados, comenzase a ubicarse fuera de sus ámbitos nacionales originarios ${ }^{4}$. Desde que esos nodos o filiales optaron por localizarse en grandes áreas urbanas de otros países, estas, al intensificar su interconexión, pasaron a formar parte, con desigual presencia, de la red global de ciudades. Así, desde el momento en que un área urbana logró articularse a la dinámica global y, por tanto, a esta red global, con ello comenzó a aumentar el número de redes productivas (de bienes y de servicios) o de consumo que localizaron en ella sus nodos.

Desde el momento en que empezó a aumentar la presencia de diversos circuitos globales en una determinada entidad nacional y, por lo tanto, de los componentes de esos circuitos en alguna (o algunas) área urbana de esta entidad, la respectiva base económica comenzó a ser objeto de cambios de diversa naturaleza; en lo fundamental, esto se debe a que para poder acoger a esos componentes, también se hizo necesario que allí se estableciese y desarrollase un conjunto de actividades requerido para el adecuado funcionamiento y despliegue de las filiales o nodos de dichos circuitos globales. Desde el momento en que esto comenzó a producirse, estas actividades y funciones pasaron a jugar un papel protagónico en la conformación de una economía urbana que empieza a presentar diferencias substanciales con la que había caracterizado a la ciudad industrial en sus diversas modalidades.

Entre esas actividades que comienzan a destacarse, cabe mencionar en especial: i) servicios a la producción, en especial financieros, jurídicos, de consultoría, publicidad, informática, ingeniería y arquitectura, etc.; ii) tareas de dirección, gestión, coordinación y control de las filiales de las redes globales

\footnotetext{
4 Según la UNCTAD (2008), mientras en 1993 se contabilizaba un número total de 37.000 ETN con 175.000 filiales, en el año 2007 el total de estas empresas había ascendido a 78.400 y el número de filiales a 780.000 .
}

y de las redes nacionales en proceso de globalización; iii) actividades industriales relacionadas y/o al servicio de las redes globales; iv) actividades de distribución y comercialización de productos globales destinados al consumo de las familias y de las empresas; y v) un conjunto de actividades relacionadas con los negocios inmobiliarios y la industria de la construcción, que adquirieron especial relevancia en la mayor parte de estas áreas urbanas. La aparición y la expansión de actividades de esta naturaleza, buena parte de las cuales se desarrollaron articuladas a las cadenas globales, tiene su origen y justificación en la propia conexión de componentes de la economía nacional a esas cadenas. Con el avance de la globalización, estas actividades tendieron a adquirir un papel relevante en la recuperación del dinamismo de las economías urbanas involucradas.

Por otra parte, el crecimiento de este complejo conjunto de actividades redundó en muchos de estos países en un aumento de los correspondientes niveles de empleo y de ingresos y en la generación de una demanda adicional por nuevos tipos de servicios a las familias, cuyo desarrollo también tuvo una importante incidencia en la reestructuración de la base económica de las áreas urbanas afectadas por estos procesos. Con ello se produjeron cambios cuantitativos y cualitativos en diversos servicios, que debieron atender a una demanda mucho más exigente en rubros como educación, salud, religión, esparcimiento, turismo, cultura, etc., muchos de los cuales también son parte de circuitos globales, o bien, pasan a formar parte de ellos. Al mismo tiempo, en la mayor parte de los casos, la inserción en la dinámica globalizada incrementó el flujo de visitantes globales, lo que generó una demanda por diversos servicios en rubros como hotelería, gastronomía y comercio, que también contribuyeron a la mutación y diversificación de la base económica de cada una de estas ciudades. La consolidación y expansión de este diversificado conjunto de actividades también contribuyó a la progresiva terciarización de la base económica urbana.

Además de sus nuevos componentes globalizados, donde los servicios avanzados cumplieron un papel clave en la articulación entre diversos circuitos productivos y comer- 
ciales, la nueva base económica continuó incluyendo una multitud de actividades productivas tradicionales, especialmente relacionadas con servicios cotidianos, muchos de ellos de baja productividad e informales, con lo cual se desarrolló una compleja imbricación entre procesos globales y locales, que en buena parte de los casos adoptaron modalidades específicas en cada área urbana. En esta dirección, como han comprobado diversas investigaciones sobre algunas grandes metrópolis de la región (Silveira, 2007; Duhau y Giglia, 2007), la introducción, aceptación y consumo de un conjunto de productos globales se propagó en un lapso relativamente corto hacia los mercados más tradicionales y populares, tanto formales como informales, contribuyendo a generar $y$ a expandir múltiples circuitos de distribución y comercialización de gran dinamismo, con una creciente utilización, legal o ilegal, de diversos productos globales.

Estos procesos, que se han expandido en prácticamente todas las grandes áreas metropolitanas latinoamericanas, utilizando las más variadas ramificaciones de la economía local, también incluyen la aparición y la propagación de diversas redes conformadas en torno a actividades del crimen organizado, en campos tales como narcotráfico, prostitución, tráfico de armas, etc., las cuales también incrementaron su importancia desde cuando pasaron a operar organizadas como cadenas globales (Naim, 2006). Sobre esta base, utilizando diversos mecanismos de reciclaje de ingresos y salarios, han llegado a tener un impacto creciente en la dinamización de la base económica de algunas islas urbanas que han cobrado importancia en muchas grandes áreas metropolitanas del mundo $y$, en particular, en las de varios países latinoamericanos. En algunas de ellas, dada la magnitud de los recursos que movilizan y de los mecanismos de cooptación utilizados, estas redes han podido asumir un control prácticamente total de ciertas partes de dimensión significativa de esas áreas urbanas, aumentando su fragmentación y su ingobernabilidad.

El conjunto de actividades y procesos que conforman esta base económica urbana, en virtud de sus intrincados encadenamientos, tuvo un importante impacto en la reactivación del crecimiento de esas grandes metró- polis y contribuyó a que fuese en ellas donde se verificase la más importante concentración relativa de riqueza y de poder de cada ámbito nacional lo cual, a su vez, incidió por diversos canales y mecanismos a la dinamización y retroalimentación directa e indirecta de su crecimiento.

\section{Flujos, lugares y redes metropolitanas de áreas urbanas}

¿Cómo afectó el desarrollo de esta nueva base económica urbana a la organización y al funcionamiento de las ciudades respectivas? Al respecto, ante todo hay que tener en cuenta que bajo las condiciones generadas por los avances de la liberalización y de la informacionalización, un número significativo de estas áreas urbanas, al imbricarse en la dinámica global, pasaron a funcionar bajo nuevas modalidades de conectividad y de movilidad. Y, luego, que en esa situación, en la que se desplegaba un número ascendente de flujos de diversa naturaleza, estos al momento de escoger el destino territorial que consideraban como más adecuado para su valorización, mostraron una marcada preferencia por la áreas mejor posicionadas en la red global de ciudades. Si bien esto concierne principalmente a los flujos de capital, que son los que marcaron la dirección dominante, los flujos de otra naturaleza (personas, información, bienes, etc.) por razones similares también se orientaron en gran parte hacia las mismas áreas y ciudades.

A medida que estos flujos comenzaron a materializarse en distintas áreas urbanas, la consecuente llegada de diversos nodos de redes o circuitos globales incidió para que se iniciase en ellas esa metamorfosis urbana que, bajo la combinación de desestructuración y reestructuración, culmina en la emergencia de dicha nueva forma urbana. Este proceso, que es específico a esta fase de modernización capitalista, ha sido presentado por Castells (2001: 498) como uno en el que "la lógica enfrentada del espacio de los flujos y del espacio de los lugares estructura y desestructura simultáneamente las ciudades, que no desaparecen en las redes virtuales, sino que se transforman en la interfaz entre la comunicación electrónica y la interacción física mediante la combinación de redes y lugares". Es justamente en esta interacción, producto 
de las relaciones regulares y recíprocas, entre la ciudad invisible (relacional) y la ciudad visible (material), donde estas relaciones son continuamente modificadas por la aparición de nuevos modos de movilidad que, por una parte, aumentan las potencialidades de la ciudad invisible, y por otra, reafirman la pertinencia de la ciudad visible (Remy, 2001: 149).

En esta evolución, al intensificarse las relaciones regulares y recíprocas entre lo relacional y lo material, al mismo tiempo que lo relacional influye sobre lo material, lo material (básicamente, el medio ambiente construido) lo hace sobre la forma en que se manifiesta lo relacional, en un proceso en el que tiende a complejizarse de más en más la organización y el funcionamiento de estas grandes aglomeraciones urbanas. En estos procesos, la ciudad invisible se manifestó en diferentes planos (o capas), en muchos casos inconexos, que corresponden a distintos circuitos en los que participan y se imbrican actividades y/o sectores de la respectiva economía urbana; sin embargo, eslabones de esas cadenas tendieron a materializarse con preferencia allí donde las economías de aglomeración existentes (que pueden presentarse en distintas partes de una misma macrorregión) podían ofrecerles mayores ventajas para su crecimiento y expansión. Como consecuencia de esta materialización de lo relacional, se produjo la emergencia de un territorio organizado en torno a múltiples subcentralidades ("areolas" según Remy), que se han constituido en la base de una estructura metropolitana policéntrica, en la que tiende a atenuarse la importancia de la proximidad.

Con ello, comenzó a producirse la evolución desde una estructura metropolitana nítidamente delimitada, típica del patrón de urbanización de imperante en fases anteriores, hacia macrorregiones urbanas, difusas y reticuladas, en algunas de cuyas "areolas", tendió a producirse una mayor concentración de nodos de distintas actividades articuladas en circuitos o cadenas globales. ¿Cuáles fueron las condiciones que permitieron y favorecieron esta mayor dispersión territorial? En lo fundamental, esto se sustentó en que bajo los efectos de la generalizada y creciente difusión y adopción de las TIC, aunado a la intensificación de la movilidad, en la cual el incontrolable aumento de la utilización del automóvil desempeñó un papel cada día más importante, se produjo una sustantiva reconfiguración y ampliación del campo metropolitano de externalidades, lo que significa que "[...] los nuevos campos de externalidad no tienen ya una forma de área compacta, ni un radio tan limitado, sino que se configuran como retículas articuladas en centros y sistemas urbanos pequeños o grandes, en extensiones territoriales macrorregionales" (Dematteis, 1998: 25).

En otras palabras, las externalidades que aparecían asociadas a la concentración de la actividad productiva (y de la población) en la forma urbana relativamente bien delimitada, dominante en la fase anterior, dieron paso a las externalidades en red cuando aqueIla forma comienza a ser reemplazada por un patrón de urbanización que se expresa como un área metropolitana expandida, en la que coexisten diversas subcentralidades articuladas por nuevas modalidades de conectividad y movilidad en un territorio predominantemente urbano de dimensión regional. De esta manera, desde ese momento las externalidades ya no están referidas a una mancha urbana compacta, sino a una red metropolitana de áreas urbanas imbricadas por nuevas modalidades de conectividad (Trullén \& Boix, 2003; Boix, 2004). Como resultado de esta ampliación y reticulación del campo de externalidades, se impusieron condiciones más favorables para el establecimiento y la profundización de las relaciones productivas y residenciales en un ámbito geográfico cada día más extenso, donde se intensificó la interconexión entre actividades y personas localizadas en diversas partes de un territorio metropolitano en continua expansión. Bajo los efectos de estos cambios, un número creciente de habitantes y de actividades de diversos pueblos o ciudades medias y pequeñas, aledañas a las aglomeraciones principales, profundizaron sus conexiones y articulaciones en el ámbito de esa red metropolitana de áreas urbanas. 


\section{Nuevos comportamientos locacionales y autoorganización urbana}

¿Cómo incidió este conjunto de cambios en el comportamiento locacional de los principales actores urbanos? Y ¿cuál fue su impacto en la metamorfosis de cada ciudad? Para analizar esto, es necesario observar cómo los cambios que se produjeron con los avances de la informacionalización y de la liberalización económica reafirmaron o modificaron el comportamiento de aquellos actores cuyas decisiones locacionales tienen mayor incidencia en el desarrollo urbano, como es el caso, en especial, de las familias y de las empresas.

El interés en focalizar este análisis en los efectos territoriales del comportamiento locacional de las familias y de las empresas se justifica en que aquí se considera que esa metamorfosis que afecta la evolución de un área urbana es producida por modificaciones en el proceso de autoorganización que resulta de una infinidad de decisiones y acciones adoptadas cotidianamente por estos actores. Aun reconociendo que estas decisiones y acciones están constreñidas o acotadas por las regulaciones urbanas vigentes en cada momento, se entiende que son fundamentalmente ellas las que determinan el carácter y la dirección de la respectiva metamorfosis urbana. Al respecto, se asume que, como sostiene Johnson (2003: 37), cada ciudad se desarrolla como un sistema emergente, esto es, como "un orden global construido a partir de interacciones locales", caracterizado por una "[...] personalidad que se auto-organiza a partir de millones de decisiones individuales". Donde es importante señalar que la autoorganización es un proceso que ha ido cobrando importancia con el propio aumento de la complejidad de los sistemas urbanos y que, en cada circunstancia, evolucionan condicionados por las tendencias constitutivas dominantes en el entorno sistémico del que forman parte.

Los factores que encuadran este tipo de dinámica social fueron soslayados sistemáticamente por los intentos de planificación racionalista que pretendieron reorganizar $y$ racionalizar el funcionamiento de las ciuda- des conforme a ideas y propuestas basadas en el supuesto de que una autoridad urbana tenía la capacidad para manejar y encauzar el comportamiento de una multitud de actores sociales conforme a un plan preestablecido. Por ello, ahora, luego del fracaso de las experiencias basadas en ese enfoque de planificación, se tiende a aceptar que, como afirma Remy (2001: 148), "[...] la coherencia del proceso no resulta de la imposición de una doctrina urbanística bajo el apremio de una autoridad. La intervención política no es la única base de una racionalidad espacial, fuera de la cual no se encontraría más que el caos. La intervención política y urbanística tiene mucho más peso cuando ella se inserta en un proceso que toma fuerza independientemente de ella". Entendida de esta manera la dinámica urbana, resulta lógico concluir que para analizar como se procesaron las mutaciones que caracterizan a estos sistemas emergentes, ante todo es necesario observar con especial atención los cambios en el comportamiento locacional de las familias y de las empresas, considerando también cómo inciden en ellos, tanto las restricciones impuestas por el respectivo entorno institucional, como el marco regulatorio existente.

Lo que aquí se sostiene, es que durante las últimas décadas efectivamente se produjeron cambios en el comportamiento locacional tanto de las familias y de las empresas, y que en ello tuvo una singular incidencia el hecho de que entonces, bajo las condiciones generadas por la liberalización económica, se ampliaron significativamente las opciones para su localización en un territorio que, por ello mismo, se fue haciendo cada vez más extenso. Y esto, a su vez, se debe a que bajo la dinámica del nuevo impulso modernizador se desencadenaron tres procesos que pueden considerarse como constitutivos del mismo: en primer lugar, la ya mencionada ampliación y reconfiguración del campo metropolitano de externalidades que, bajo los efectos de la difusión de las TIC y de la intensificación de la conectividad y de la movilidad, redujo progresiva y significativamente el peso del factor distancia en las decisiones de localización de ambos grupos de actores, permitiendo la elección de lugares más alejados de la parte central del territorio metropolitano; en segundo lugar, los cambios observados en el enfoque 
de la gobernanza urbana, que evolucionó hacia una modalidad de corte empresarialista (Harvey, 1989) que, al estar regida por una creciente influencia del principio de subsidiaridad estatal, amplió esa libertad de la que se beneficiaron familias y empresas para escoger su localización en un territorio urbano más extenso; y, en tercer lugar, también influyó en esta dirección el significativo y persistente aumento de una oferta inmobiliaria de nuevas localizaciones y nuevos productos, que impulsó la incorporación de áreas, fundamentalmente periurbanas, a esa dinámica de expansión metropolitana (De Mattos, 2008). Estos cambios aunados a los continuos aumentos de la conectividad y la movilidad, junto al incontenible crecimiento de la utilización individual y familiar del automóvil, se encuentran en el origen de la intensificación de los procesos de metropolización expandida y difusa.

En lo que específicamente tiene relación con las familias, varios factores incidieron para que su comportamiento locacional evolucionara en esta dirección. En primer lugar, el incremento del ingreso personal medio que se observó con distinta intensidad en la mayoría de estos países, que permitió a un número significativo de familias el acceso a una mayor superficie residencial, lo cual, a su vez, redundó en un persistente aumento del consumo de suelo habitacional per capita y, en consecuencia, en una continuada caída de la densidad urbana, fenómeno este que se ha verificado en casi todo el mundo ${ }^{5}$. En segundo lugar, la fuerte preferencia de las familias por la vivienda unifamiliar con jardín, lo cual aparece como uno de los factores que más influyeron en la acentuación de la expansión territorial metropolitana. En tercer lugar, diversos cambios que se produjeron durante las últimas décadas en la composición familiar urbana, donde se destaca la tendencia a la formación de unidades familiares más pequeñas, lo cual incidió en un incremento de la

\footnotetext{
5 La última estimación realizada por Demographia (2009) sobre la población de las áreas urbanas de 138 entidades geográficas de todo el mundo, confirmó la existencia de una fuerte asociación entre baja densidad poblacional urbana y altos ingresos (producto interno bruto per cápita corregido por paridad de poder de compra.
}

demanda por nuevas viviendas. $Y$, finalmente, el hecho de que como consecuencia de la continuidad del proceso de urbanización de la economía y de la población, continuó creciendo -aun cuando en forma declinante- el número absoluto de habitantes en gran parte de las ciudades principales, en particular, de las latinoamericanas.

La confluencia de estos factores contribuyó a aumentar la superficie urbanizada, lo cual significó un estímulo adicional a la expansión territorial de estas aglomeraciones. De manera diferenciada, esta tendencia a localizarse en la parte externa de las grandes aglomeraciones urbanas, involucró tanto a las familias de ingresos altos y medios como a las de menores ingresos. En cuanto a las primeras, como ya se ha señalado, dada su preferencia por la vivienda unifamiliar, al aumentar su ingreso medio mejoró su situación para acceder a localizaciones más distantes de las áreas centrales, lo cual impulsó un continuo incremento de la utilización de suelo adicional. En lo que concierne a los sectores de menores ingresos, se ha comprobado que en casi todo el mundo se produjo su desplazamiento hacia las partes más pobres de la periferia urbana, donde el precio de la tierra es más bajo, muchas veces hacia áreas aún no urbanizadas, tendencia a la que en el caso de las metrópolis latinoamericanas contribuyeron tanto los programas de vivienda social con apoyo estatal, allí donde los ha habido, como los mercados inmobiliarios informales y la ocupación ilegal de tierras periféricas (UN-HABITAT, 2003).

En este sentido, puede afirmarse que el conjunto de estrategias y decisiones locacionales de las familias contribuyeron a retroalimentar la tendencia a la metropolización expandida, desde que una parte significativa de ellas, más allá de sus respectivos niveles de ingreso, tendieron a establecer su residencia en lugares más distantes de las partes centrales de cada una de estas aglomeraciones. Como han confirmado para la mayor parte de los casos los resultados de los dos últimos censos de población en América Latina, esta tendencia a la periurbanización, que afectó prácticamente a todos los sectores sociales, ha sido acompañada por una importante pérdida de población de las áreas centrales más antiguas y consolidadas de las grandes 
metrópolis, en beneficio de múltiples lugares de los bordes metropolitanos. Si continúa aumentando el ingreso medio de las familias y, por lo tanto, la demanda por espacio residencial y el consumo de tierra por habitante, es poco probable que se detenga la tendencia a la expansión territorial metropolitana, aun si se produjese una atenuación e, incluso, una reversión del crecimiento de la población, como ya ha estado ocurriendo en algunas de estas grandes ciudades.

En este crecimiento expandido también incidió el fuerte aumento de una oferta inmobiliaria de conjuntos de viviendas cerrados y amurallados, destinada principalmente a sectores de ingresos altos y medios. Esta oferta ha incluido desde pequeños grupos de viviendas, hasta las denominadas ciudades valladas (Hidalgo, 2004), entre las cuales, por su dimensión y/o por su concepción, algunas ya llegaron a constituirse en verdaderas ciudades satélites privadas (Alphaville en São Paulo, "ciudad-pueblo" Nordelta en Buenos Aires, Piedra Roja en Santiago, entre otras). Ante la generalizada percepción, real o imaginada, sobre el aumento de la delincuencia y la violencia urbana, este tipo de configuración se ha transformado en un destino de alta rentabilidad para los capitales móviles en busca de nuevos negocios inmobiliarios. Este producto inmobiliario, al mismo tiempo que ha contribuido a la generación y proliferación de nuevas modalidades de fragmentación urbana, también ha hecho una importante contribución al fortalecimiento de la tendencia a la metropolización expandida.

En lo que concierne a la localización de las empresas, más allá de algunos comportamientos específicos, en la mayor parte de las grandes aglomeraciones urbanas se afirmó su preferencia por una mayor dispersión territorial, lo que puede considerarse como otra tendencia genérica de la actual metamorfosis urbana. Esta tendencia aparece asociada al hecho de que muchas de las funciones y actividades que en la ciudad industrial tendían a ubicarse en la mayor proximidad posible de la ciudad central, ahora aprovechan condiciones favorables para optar por localizaciones más distantes, dentro del área expandida de esas aglomeraciones. En la consolidación de estas condiciones incidieron varios de los cambios producidos con el avance de la nueva dinámica económica: por una parte, la descomposición de tareas impulsada por las empresas organizadas en red, que implica la separación física entre las tareas de dirección y gestión y los procesos productivos; por otra, la ampliación reticulada del campo metropolitano de externalidades, que permitió el aprovechamiento de las economías de aglomeración más allá de la ciudad compacta del pasado; y, por último, los cambios en los sistemas y en las condiciones en transportes y comunicaciones que operaron en beneficio de una localización en áreas más alejadas dentro del ámbito de la red metropolitana en expansión.

Esta paulatina traslación hacia el periurbano involucró tanto a las plantas manufactureras, así como también a las sedes corporativas y oficinas centrales de las grandes empresas, que buscaron alejarse de las áreas centrales más congestionadas y contaminadas. En particular, un número creciente de establecimientos y talleres manufactureros tendió a trasladarse hacia lugares periurbanos en busca de terrenos de mayor dimensión y de menor costo; por su parte, las actividades de dirección y gestión también optaron por desplazarse hacia centralidades alternativas, conformadas con la propia expansión territorial de cada aglomeración y que, en muchos casos, se ubicaron en zonas del periurbano próximas a los sitios de residencia de sus ejecutivos y trabajadores de ingresos más elevados.

De tal forma, también el comportamiento dominante en las decisiones y en las acciones de localización adoptadas por empresas de diversa naturaleza y dimensión mostró una fuerte preferencia por sitios cada vez más alejados de la parte central de las aglomeraciones metropolitanas. Frente a esta tendencia a la periurbanización, en muchos casos, diferentes instancias gubernamentales desplegaron esfuerzos orientados a frenar o controlar la metropolización expandida emergente; sin embargo, la fuerza incontenible de la dinámica autoorganizativa sustentada en el comportamiento locacional de un número cada día mayor de familias y de empresas, hizo que por lo general estos esfuerzos no pudieran lograr mucho más que alterar parcialmente dicha tendencia, pero en ningún caso revertirla. 


\section{Metropolización expandida, fragmentación y policentrismo en la forma urbana emergente, metropolización expandida y policéntrica}

El hecho de que las familias y las empresas puedan disponer ahora de una gama mucho más amplia de opciones de localización en un territorio metropolitano en expansión tuvo una incidencia decisiva en la transición hacia una forma urbana substancialmente diferente de aquella que había caracterizado a la ciudad de la época industrial-desarrollista, transición que constituye uno de los aspectos medulares de la metamorfosis que entonces comenzó a cobrar fuerza. En concreto, fue bajo las condiciones establecidas en este nuevo impulso modernizador, que comenzó a producirse un progresivo desdibujamiento del tipo de ciudad que se había caracterizado por " $[. .$.$] la existencia de un gradiente den-$ simétrico en sentido centro-periferia, tanto en términos de población como de actividad y empleo, junto a la identificación de unos límites externos bastante netos frente al entorno rural [...]" (Méndez, 2001: 145). Con ello, se inició la "evolución de las formas, funciones y estructuras urbanas, transformadas por el estallido de la antigua ciudad y por la urbanización generalizada", tal como propuso Lefebvre (1979: 24), quien ya al inicio de la década de los setenta caracterizó este proceso como una revolución urbana que es, justamente, la que ahora se está materializando a escala global.

¿Y cuáles son las formas, las funciones y las estructuras urbanas que aparecen como producto de esta revolución? En remplazo de lo que ahora se desdibuja, aparece "una trama continua de asentamientos, organizada alrededor de un gran número de focos nodales especializados en una vasta región multicentrada", cuyo "modelo ideal [...] puede ser definido como una ciudad sin centro o como una región urbana organizada alrededor de los fragmentos desparramados de la explosión del centro" (Dematteis \& Governa, 2001: 38). Fue así que, en lo esencial, en este período, bajo los efectos de una verdadera explosión de la conectividad y de la movilidad, se establecieron condiciones que favore- cieron la expansión descontrolada de aquella ciudad compacta, de límites relativamente nítidos, para dar paso a una aglomeración expandida, difusa, discontinua, policéntrica, de dimensión regional. Lo cual, más allá de los aspectos morfológicos, implica cambios fundamentales en la organización y en el sentido mismo de la vida urbana,

¿Corresponde este tipo de evolución a lo que se está observando actualmente en las principales áreas metropolitanas latinoamericanas? Hoy en día es posible encontrar un buen número de testimonios que permiten responder afirmativamente a esta pregunta. Así, por ejemplo, en una investigación sobre la expansión metropolitana de la ciudad de México se concluye que "[...] la megaciudad contemporánea presenta una expansión más policéntrica, creando un patrón más asociado a redes y con límites y fronteras menos precisas difícilmente definibles", lo cual se expresa en "[...] un patrón de expansión con tendencias a la dispersión urbana que incorpora progresivamente pequeños pueblos y periferias rurales dentro de un sistema metropolitano cada vez más amplio y complejo" (Aguilar, 2002: 123). Cuando se analiza la dinámica que subyace en la conformación de este patrón, se puede comprobar que el crecimiento económico y la expansión territorial de estas aglomeraciones se sustenta en una intensificación de la articulación técnica y funcional entre sus distintas partes, tal como plantea Araujo (2001: 27) para el caso de São Paulo: "la estructura industrial del conjunto de las regiones que configuran el entorno de la Región Metropolitana de São Paulo presenta un elevado grado de integración técnica y funcional con esta. Puede afirmarse que en esa porción del territorio paulista se encuentra en curso un extenso proceso de metropolización, integrando aglomeraciones urbanas metropolitanas (São Paulo, Campinas y Santos) y no metropolitanas (São José Dos Campos y Sorocaba) en una gran área socioeconómica".

Lo importante es que al aumentar la conectividad y la movilidad, en aquellos casos en que el entorno morfológico lo permitió, también se incrementó en forma progresiva el número de ciudades medias y pequeñas ubicadas en el área de influencia inmediata metropolitana, que intensificó su articulación 
con el subsistema central. Es así, por ejemplo, que para el caso de la metropolización expandida en Ciudad de México, se comprobó que "la mayor parte del crecimiento ya no se da dentro del perímetro urbano, sino que se ha trasladado a un número importante de ciudades medias y pequeñas dentro de una amplia región metropolitana a una distancia considerable del núcleo central de la megaciudad" (Aguilar, 1999: 148). Esta dinámica que combina articulación técnica y funcional y metropolización expandida, en el contexto de una red metropolitana de áreas urbanas, se ha podido observar no solo en las metrópolis de mayor dimensión (São Paulo, Ciudad de México, Buenos Aires, Lima, Río de Janeiro, Bogotá, Santiago de Chile, etc.), sino también en algunas de menor dimensión como, entre muchas otras, en Belo Horizonte, Cali, Ciudad de Panamá, Concepción, Córdoba, Guadalajara, Medellín, Monterrey, Montevideo, San José de Costa Rica, Pôrto Alegre y Quito.

En este escenario, numerosas nuevas subcentralidades comenzaron a cobrar relevancia en la organización y el funcionamiento de la forma urbana emergente. Estas subcentralidades incluyen una amplia variedad de modalidades y de expresiones arquitectónicas y urbanísticas, que van desde las que resultaron del fortalecimiento, diversificación y ampliación de actividades comerciales tradicionales para el consumo cotidiano local, muchas veces configuradas linealmente a lo largo de ciertas arterias o corredores de antigua tradición comercial, hasta los nuevos centros de negocios.

En la mayoría de estas metrópolis, junto al incontenible crecimiento del consumo, se ha producido la revitalización y la modernización de muchos de sus antiguos corredores comerciales, con fuerte impacto en la reorganización urbana: en buena parte de los casos estos corredores también se beneficiaron con la descentralización de una pluralidad de servicios personales, en especial en áreas como salud, educación, esparcimiento, religión, administración pública, etc., orientados a satisfacer la demanda de los habitantes de sus respectivos entornos locales, cuyo acceso a las áreas centrales tradicionales se ha hecho más difícil con su propia expansión territorial. La diferencia entre estas centralidades y las existentes en el pasado, se encuentra principalmente en su complejización, producto de una diversificación que no solo abarca la exacerbación del consumo, sino también un aumento de la oferta de servicios, lo cual les ha permitido situarse como alternativas efectivas al centro histórico de la ciudad. Es así, que aun cuando muchos de estos centros todavía conservan una importante concentración de funciones terciarias, el paulatino fortalecimiento de la dotación de servicios en las centralidades alternativas, ha redundado en que para diversas dimensiones de la vida cotidiana los mismos estén tendiendo a ser menos utilizados y frecuentados.

A estas subcentralidades lineales se han sumado otras formadas en torno a configuraciones inherentes a esta fase, entre las que se destacan especialmente los "shopping centers" o "malls" que, en la mayor parte de los casos, funcionan en base a una diversificada mezcla de actividades comerciales y de servicios, donde aparece como componente básico un amplio conjunto de nodos de cadenas globales orientadas al consumo. Muchas de estas concentraciones territoriales han tenido un fuerte impacto en la transición de las áreas urbanas respectivas hacia una forma multicéntrica dispersa, más adecuada a la creciente difusión y utilización del automóvil, lo que incidió en una sustantiva modificación de su organización y funcionamiento.

Asimismo, en varias de estas áreas metropolitanas, también empezó promoverse la realización de grandes proyectos urbanos, cuya concepción y diseño se inspiró por lo general en experiencias exitosas de algunos países desarrollados. Ofrecidos como una opción para satisfacer el interés de muchas empresas por desplazar sus cuarteles generales y sedes corporativas hacia lugares más alejados de las zonas más congestionadas, muchos de ellos son concebidos como verdaderos ornamentos urbanos (Esteban, 2007) que, por sus peculiaridades $-y$, en ciertos casos, por su extravagancia-, resultan de utilidad para la promoción externa de la metrópoli en que están localizados. En buena parte de los casos, estos proyectos ofrecieron alternativas de inversión de elevada rentabilidad a la sobreoferta de capitales existentes en momentos de elevado crecimiento económico, por lo que su ejecución ha estado frecuentemente 
asociada a la realización de grandes negocios inmobiliarios.

¿Cómo se materializó esta evolución hacia la policentralización de las áreas de negocios y servicios en estas metrópolis? En general, se puede verificar que ella formó parte de una tendencia a la dispersión territorial de las actividades terciarias, en particular de las sedes y oficinas corporativas, sedes bancarias y financieras, centro comerciales diversificados y especializados, hoteles de cadenas internacionales, restaurantes, etc. Algunos ejemplos permiten documentar las tendencias dominantes en las principales ciudades latinoamericanas: en Ciudad de México, el desplazamiento de oficinas de negocios, sedes bancarias y financieras, hoteles de cadenas internacionales, etc., que se inició todavía en el período industrial-desarrollista, se orientó primero desde el centro histórico en dirección al Paseo de la Reforma y Polanco y más tarde hacia el sur de la ciudad, para culminar más recientemente en una de las operaciones inmobiliarias de mayor magnitud de toda América Latina, en el Centro Corporativo Santa Fe (Parnreiter, 2002; López Levi, 2007). En São Paulo, numerosos estudios han documentado y analizado el desplazamiento del núcleo principal de negocios desde el centro histórico, primero hacia la Avenida Paulista y luego, desde la década de los 90, hacia el cuadrante sudoeste, originando allí un complejo arquitectónico de gran dimensión e impacto urbano (Frúgoli Jr., 2000; Iglecias, 2001; Fix, 2007). En Santiago de Chile, al desplazamiento inicial de algunos componentes del centro de negocios en dirección a la Av. Providencia, siguió una mayor dispersión hacia el oriente (El Golf, Av. Apoquindo), para culminar con la creación de un centro terciario avanzado en la Ciudad Empresarial en un arrabal inaccesible pocas décadas atrás $y$, a partir de allí, hacia áreas ya más alejadas del centro fundacional. En Lima, "el único centro metropolitano que Lima mantuvo por muchas décadas se ha desdoblado en múltiples centros especializados y redes de actividades informacionales, industriales, comerciales y culturales. Estos centros han generado una alta densidad de actividades y flujos de capital e información, creando una nueva jerarquía espacial metropolitana" (Chion, 2002: 72), tendencia que ha tenido su principal expresión en el des- plazamiento de numerosas actividades de negocios hacia San Isidro y Miraflores (Ludeña, 2002). En Bogotá se ha cumplido un proceso similar, con el movimiento desde la localización inicial en las proximidades de la plaza Bolívar, primero hacia el Centro Internacional Tequendama y luego hacia Chapinero, para continuar hacia la Avenida Chile y, desde allí, hacia otros lugares del norte de la ciudad (Mertins y Muller, 2000). Esta tendencia también se puede comprobar para ciudades de menor dimensión como, entre otras, Quito, Panamá, San José y Montevideo.

Por otra parte, como un fenómeno también característico de esta metamorfosis, se observó la formación de diversas centralidades nocturnas, configuradas a partir de una concentración territorial de actividades destinadas específicamente al esparcimiento y a la gastronomía, y que, en ocasiones, también incluyen hotelería y algunas amenidades para los visitantes globales. En muchos casos, estas áreas han significado la reconversión y reactivación de algunos barrios o áreas que venían perdiendo importancia hasta el momento en que encontraron este nuevo destino. Ejemplos como los de Condesa en Ciudad de México, Vila Madalena en São Paulo, Palermo Soho y Palermo Hollywood en Buenos Aires, Bellavista en Santiago, Plaza Fochs en Quito, entre muchos otros, muestran cómo está tendencia ha ganado importancia en la organización y funcionamiento de estas ciudades.

\section{Metropolización expandida polarizada y fragmentada}

Tomando en cuenta la generalización de este tipo de proceso, ¿cómo pueden sintetizarse los aspectos básicos de la imagen socioterritorial resultante al afirmarse este nuevo patrón de urbanización? Un estudio realizado para el caso de Caracas, esboza un cuadro cuyos rasgos medulares también se pueden aplicar a la situación emergente de estos procesos en otras aglomeraciones latinoamericanas, donde se destaca "la coexistencia, a veces conflictiva, de múltiples ciudades en el territorio de una metrópolis cuya sociedad se ha ido diversificando y complejizando. La heterogénea diferenciación socio-residencial producto de viejos y nuevos procesos de segregación, reflejada 
en la configuración de ghettos exclusivos para los sectores de altos ingresos, de ámbitos deteriorados o relegados a la periferia para los sectores medios y de verdaderos apartheid sociales para los grupos populares, se refuerza con la diferenciación territorial propia de las transformaciones económicas en la producción y el consumo, expresada en la emergencia de distritos financieros y negocios y de grandes equipamientos comerciales, mientras importantes áreas céntricas de la ciudad constituyen el espacio económico por excelencia de la economía informal ligada a la sobrevivencia" (Cariola y Lacabana, 2005: 174). Más allá de algunas peculiaridades que distinguen a estas metrópolis entre sí, los aspectos que aquí se sintetizan, se pueden observar en la evolución de la gran mayoría de las mismas.

Las "múltiples ciudades" a las que se hace referencia, aparecen como un componente primario de los cambios producidos por la actual metamorfosis urbana y pueden considerarse como un rasgo genérico de una forma urbana en la que se presentan fuertes contrastes, tanto entre sus áreas residenciales como entre las de la producción y el consumo. En la evolución hacia esta situación, a la que sin duda contribuyó el aumento de la segmentación de los mercados de trabajo impulsada por la reforma laboral que acompañó al proceso de liberalización económica, incidió en que hasta ahora no haya sido posible lograr avances hacia una efectiva reducción de la polarización social heredada, como lo indica el hecho de que el coeficiente de Gini ha mantenido valores muy elevados en la mayoría de los países latinoamericanos durante la década de los 90 lo que, por otra parte, corrobora que esta región continúa siendo una de las más desiguales del mundo (López y Perry, 2008). Como es evidente, la configuración de sus principales áreas metropolitanas no permaneció ajena a esta regresiva tendencia.

¿Qué repercusiones ha tenido esta situación de persistencia e, incluso, de acentuación de las desigualdades y de la polarización social en la configuración socioterritorial metropolitana? En particular, en lo que se refiere a la evolución sociorresidencial de estas aglomeraciones, una de sus más visibles y generalizadas consecuencias ha sido la acentuación del contraste entre las áreas re- sidenciales de los sectores sociales extremos. Como, además, la situación social dominante también ha contribuido a producir un continuo aumento de la violencia urbana, el temor que así se ha generado se ha situado como un factor de creciente influencia en el comportamiento de las familias con respecto a su medio residencial, contribuyendo a afirmar una tendencia hacia la reclusión residencial de las familias, sea cual sea su ubicación en la escala social. En ese escenario, en todas estas aglomeraciones se observa la coexistencia, con escasa relación entre sí, de las áreas de la opulencia, en las que han comenzado a proliferar los guetos voluntarios de los sectores de altos ingresos, con extensas zonas tugurizadas, donde los más pobres también tienden a recluirse compulsivamente (Bauman, 2005), para lo cual también recurren a distintos tipos de cerramientos, muros y rejas. $\mathrm{Y}$ esta tendencia a la reclusión, familiar o de grupos sociales, comporta otro cambio importante que afecta al funcionamiento y al paisaje urbanos: la acentuación de los procesos de fragmentación social, que implica un progresivo e irreversible debilitamiento de las relaciones entre un número creciente de partes del sistema, que pasan a funcionar como islas en el archipiélago metropolitano (Janoschka, 2002; Borsdorf, 2003).

Al mismo tiempo, y como un componente adicional de este paisaje urbano, se han desarrollado extensas áreas periféricas intermedias, ocupadas principalmente por importantes contingentes de población de ingresos medios, la cual, sobre todo cuando se ubica en la proximidad de lugares de residencia de sectores más pobres, también tiende a recurrir a diversos tipos de recintos amurallados y protegidos, como respuesta al creciente temor a la cercanía de lo que perciben como "clases peligrosas". Además, como parte relevante de ese paisaje, en el que las propuestas de los promotores inmobiliarios juegan un papel de decisiva importancia, aparecen extensas áreas residenciales verticalizadas; en ellas, se repite infatigablemente un prototipo de edificio de departamentos en altura, para cuyo diseño se adopta en forma generalizada, sin mayores variaciones, una arquitectura estandarizada y rutinaria, cuya multiplicación genera un medio ambiente construido que no presenta mayores diferencias entre una metrópoli y otra. 
Por otra parte, en lo que respecta a las partes en que se localizan las actividades orientadas a la producción y al consumo, ellas aparecen claramente diferenciadas, según sean los niveles de ingresos de los grupos sociales a los que están destinadas. En clara correspondencia con la configuración socioterritorial a la que ya se ha hecho referencia, también aquí se observa un nítido contraste entre el paisaje urbano de los lugares que están orientados a los sectores de mayores ingresos y/o a los visitantes globales, por lo general ubicados en nuevas centralidades especialmente configuradas a estos efectos, y los que están dirigidos a los grupos de menores ingresos, mayoritariamente desplazados hacia las zonas periféricas y marginales. De tal forma, al mismo tiempo que casi todas estas ciudades exhiben ostentosas escenografías concebidas especialmente para albergar a los nodos de diversas firmas globales, a los hoteles de cadenas internacionales y/o a la alta gastronomía, en contraposición, en ciertas partes de esa misma metrópoli se produce el informe amontonamiento de una infinidad de pequeños establecimientos productivos y comerciales, que configuran un inhóspito paisaje urbano, cuya mayor o menor degradación y fealdad tiene clara correspondencia con los niveles de ingresos de quienes lo utilizan. Este contraste entre unas partes y otras de un mismo ámbito metropolitano, situadas en lugares muy diferentes del mismo, generalmente muy distantes entre sí, establece una nítida diferencia entre la imagen de lo urbano visitable y lo no visitable, lo competitivo y lo no competitivo.

En este contexto, también se manifiestan múltiples expresiones, en ascenso en la mayor parte de estas ciudades, de las ya mencionadas áreas controladas por el crimen organizado, que han logrado generar numerosos y, en muchos casos, extensos fragmentos urbanos, en su mayoría infranqueables para gran parte de la población y, en muchos casos, también para las propias fuerzas policiales. En los últimos años, merced a la expansión y a la eficiencia que lograron al funcionar organizadas como cadenas globales, estas actividades han ocupado partes cada vez más extensas de los respectivos territorios metropolitanos, en procesos que en muchos de ellos son hasta ahora inmanejables.
Finalmente, frente a este cuadro, se puede afirmar que cuando se observa el resultado de esta evolución de las grandes metrópolis latinoamericanas, lo que se encuentra son conglomerados en continua y descontrolada expansión, donde aparecen múltiples y diversos ámbitos sociales, visiblemente contrastados entre sí, que funcionan en forma fragmentada, como si fuesen islas procedentes de diferentes realidades geográficas, pero que ahora forman parte de un mismo archipiélago. Por ello, cuando se hace referencia a la supuesta belleza de una determinada metrópoli de esta parte del mundo, a lo que se está aludiendo es apenas a una parte de ella, que es la que promueven las agencias de viaje y las líneas aéreas, la ciudad visitable, esto es, la que se ofrece a los viajeros globales. Consideradas en su conjunto, cada una de estas entidades esquizoides, exhiben algunas partes, generalmente no demasiado extensas en relación a su superficie total, que pueden considerarse como hermosas o atractivas, pero que conviven con otras partes de la misma entidad, generalmente de enorme extensión, a las que sería muy difícil aplicar calificativos del mismo tenor.

\section{Consideraciones finales}

Aun reconociendo la importancia de algunas diferencias que han presentado distintas ciudades a lo largo de esta fase, las tendencias analizadas avalan la conclusión de que los cambios que han modificado su estructura, organización, funcionamiento y apariencia han evolucionado en las principales metrópolis latinoamericanas en una dirección similar a las identificadas en otras partes del mundo. De hecho, lo fundamental de esa evolución corresponde plenamente con lo que ya a comienzos de la década de los años setenta había sido anticipado por Lefebvre como parte de una revolución urbana que, en su opinión, estaba conduciendo a lo que caracterizó como una sociedad urbana: "de hecho, el estallido de las ciudades históricas se acompaña de la urbanización generalizada, que no representa sino la degradación de la ciudad histórica y que podemos denominar como su 'ruralización'. La urbanización generalizada no ha generalizado solamente la especulación inmobiliaria; ella no ha acompañado solamente la comercialización del espacio; ella ha acarreado, en lugar de 
la superación de la relación ciudad-campo, un magma, un caos, en los cuales la ciudad y el campo se entremezclan confusamente" (Lefebvre, 1972: 153),

Con las lógicas particularidades que corresponden a diferentes configuraciones urbanas, las tendencias generales que aquí han sido destacadas se pueden encontrar, obviamente, con desigual intensidad, en todas las metrópolis expandidas a medida que ellas se han ido imbricando en esta nueva fase de modernización capitalista; de esta manera, se ha afirmado la evolución hacia una forma urbana sustantivamente distinta a aquella que se había impuesto con el primer avance de la industrialización. Como se ha tratado de mostrar en este trabajo, los factores que tuvieron mayor incidencia en esta evolución, solamente pueden explicarse en el contexto de los cambios constitutivos que explican la nueva dinámica de acumulación y crecimiento globalizada.

Aun cuando en períodos anteriores, incluso en los mismos orígenes del proceso de formación de las sociedades capitalistas, ya eran perceptibles indicios de muchas de las tendencias que marcan el avance hacia esta forma urbana, su expresión actual es cualitativa y cuantitativamente diferente a la que se había conformado en las grandes ciudades latinoamericanas en el período industrial-desarrollista. Desde que estas tendencias pueden considerarse como inseparables de la nueva dinámica global, es lógico concluir que esta metamorfosis urbana habrá de afectar inevitablemente a todas las grandes ciudades en proceso de globalización, más allá de la persistencia y/o fortalecimiento de las específicas señas de identidad de cada una de ellas.

De esta conclusión se puede inferir otra, de crucial importancia para la discusión sobre la posible evolución futura de las grandes aglomeraciones urbanas: si se acepta que la actual metamorfosis urbana está condicionada estructuralmente por tendencias constitutivas de la nueva dinámica de acumulación y crecimiento, es lógico prever que toda propuesta de transformación que busque impulsar un cambio radical en la configuración actual de estas áreas metropolitanas, deberá considerar necesariamente la previa modificación de dichas tendencias $-y$, por lo tanto, de los factores que las determinan-, desde que son ellas las que modulan la transición hacia esa nueva forma urbana. Reafirmar la importancia de los condicionamientos estructurales de la dinámica social, resulta especialmente importante si se considera que en la literatura reciente sobre esta cuestión, algunos estudios sustentados en fundados diagnósticos sobre las causas que permiten explicarla, han terminado con la presentación de propuestas contradictorias con lo medular de esos diagnósticos; esto es, soslayando que para poder implementar lo que se propone, se requeriría una dinámica socioeconómica radicalmente distinta a la previamente diagnosticada.

Por ello, resulta importante insistir en que toda propuesta de transformación urbana debe tener en cuenta necesariamente los límites que imponen los condicionamientos histórico-estructurales inherentes a la fase de modernización capitalista en la que los procesos respectivos deberán desenvolverse. En otras palabras, en la medida que los objetivos de una determinada propuesta de gestión urbana implique una modificación de las tendencias dominantes, ello implica necesariamente la conformación de un escenario económico y social sustantivamente distinto al que ha ido emergiendo en esta nueva fase de modernización capitalista, lo que obviamente está fuera de las atribuciones y posibilidades de la así denominada planificación, regional, urbana y local y de la voluntad de los ocasionales planificadores.

\section{Referencias bibliográficas}

AGUILAR, A. G. La Ciudad de México en la Región Centro. Nuevas formas de expansión metropolitana. En: DELGADO, J. y RAMÍREZ, B. (eds.), Transiciones. La nueva formación territorial de la Ciudad de México. Ciudad de México: Plaza y Valdés Editores, 1999, p. 147-169.

AGUILAR, A. G. Las mega-ciudades y las periferias expandidas. Ampliando el concepto en ciudad de México. EURE, 2002, № 85, p. 121-149.

ARAUJO, M. F. I. Reestruturação produtiva e transformações econômicas. Região Metropolitana de São Paulo. São 
Paulo em perspectiva, 2001, vol. 15, № 1 , p. 20-30.

BAUMAN, Z. Comunidad. En busca de seguridad en un mundo hostil. Buenos Aires: Siglo Veintiuno de Argentina Editores, 2005.

BEAVERSTOCK, J. V.; SMITH, R. G. \& TAYLOR, P. J. A roster of world cities. Cities, 1999, vol. 16, No 6, p. 445-458.

BOIX, R. Redes de ciudades y externalidades. Investigaciones Regionales, 2004, No 4, primavera, p. 5-27.

BORSDORF, A. Cómo modelar el desarrollo y la dinámica de la ciudad latinoamericana. EURE, 2003, No 86, p. 37-49.

BRENNER, N. La formación de la ciudad global y el re-escalamiento del espacio del Estado en la Europa Occidental Post-fordista. EURE, 2003, No 86, p. 5-35.

CARIOLA, C. y LACABANA, M. A. Pobreza, nueva pobreza y exclusión social. Los múltiples rostros de Caracas. Caracas: Banco Central de Venezuela, 2005.

CASTELLS, M. La sociología urbana en el Siglo XXI. En: SUSSER, I. (ed.). La sociología urbana de Manuel Castells. Madrid, Alianza Editorial, 2001, p. 489-526.

CHION, M. Dimensión metropolitana de la globalización: Lima a fines del siglo XX. EURE, 2002, No 85, p. 71-87.

DEMATTEIS, G. Suburbanización y periurbanización. Ciudades anglosajonas y ciudades latinas. En MONCLUS, F. J. (ed.). La ciudad dispersa. Suburbanización y nuevas periferias. Barcelona: Centre de Cultura Contemporánia de Barcelona, 1998, p. 17-33.

DEMATTEIS, G. De las regiones-área a las regiones-red. Formas emergentes de gobernabilidad regional. En: SUBIRATS, J. (ed.). Redes, territorios y gobierno. Nuevas respuestas globales a los retos de la globalización. Barcelona: Diputació de Barcelona, 2002, p. 163-175.

DEMATTEIS, G. \& GOVERNA, F. Urban Form and Governance: the new multi- centred urban patterns. In: ANDERSON, H.; JORGENSEN, G.; JOVE, D. \& OSTENDORFF, W. (eds.). Change and Stability in Urban Europe. Form, Quality and Governance. Aldershot: Ashgate Publishing Co, 2001, p. 27-45.

DE MATTOS, C. Globalización, negocios inmobiliarios y mercantilización del desarrollo urbano. En: PEREIRA, P. C. X. e HIDALGO, R. (eds.). Producción inmobiliaria y reestructuración metropolitana en América Latina. Santiago: Instituto de Geografía, Pontificia Universidad Católica de Chile, serie GEOlibros 11, 2008, p. 23-40.

DEMOGRAPHIA. World urban areas: populations projections. Beleville: $5^{\text {th }}$ Comprehensive editions, 2009. Disponible en Internet: http://www.demographia.com/ db-worldua.pdf

DUHAU, E. y GIGLIA, A. Nuevas centralidades y prácticas de consumo en la Ciudad de México: del microcomercio al hipermercado. EURE, 2007, No 98, p. 77-95.

ESTEBAN, I. El efecto Guggengeim. Del espacio basura al ornamento. Barcelona: Editorial Anagrama, 2007.

FIX, M. São Paulo cidade global. Fundamentos financeiros de uma miragem. São Paulo: Bontempo, 2007.

FRÚGOLI Jr., H. Centralidade em São Paulo. Trajetórias, conflitos e negociações na metropole. São Paulo: Editora da Univesidade de São Paulo, 2000.

GEREFFI, G. A commodity chain framework for analyzing global industries. Durham: Duke University, 1999. Disponible en Internet: www.sjsu.edu/upload/course/ course_775/gereffix1x.pdf

HARVEY, D. From managerialism to entrepreneurialism: the transformation in urban governance in late capitalism. Geographiska Annaler, 1989, vol. 71, № 1, p. 3-17.

HELD, D. y McGREW, A. Globalización/ antiglobalización. Sobre la reconstrucción del orden mundial. Barcelona: Ediciones Paidós Ibérica, 2003. 
HIDALGO, R. De los pequeños condominios a la ciudad vallada: las urbanizaciones cerradas y la nueva geografía social en Santiago de Chile, 1990-2000. EURE, 2004, No 91, p. 29-52.

IGLECIAS, W. Impactos da mundialização sobre uma metrópole periférica: o vetor sudoeste de São Paulo. Cadernos Metrópole, 2001, No6, p. 9-53.

INDOVINA, F. (ed.). La città diffusa. Venezia: Daest, 1990.

JANOSCHKA, M. El nuevo modelo de la ciudad latinoamericana: fragmentación y privatización. EURE, 2002, No 85, p. 11-29.

JOHNSON, S. Sistemas emergentes. O qué tienen en común hormigas, neuronas, ciudades y software. México: Turner/Fondo de Cultura Económica, 2003.

KOSAKOFF, B. y LÓPEZ, A. América Latina y las cadenas globales de valor: debilidades y potencialidades. GGG Georgetown University - Universia, 2008, vol. 2, No 1, p.18-32.

LEFEBVRE, H. Espace et politique. Le droit à la ville /l. Paris: Éditions Anthropos, 1972.

LEFEBVRE, H. La revolución urbana. Madrid: Alianza Editorial, 1979.

LÓPEZ, J. H. \& PERRY, G. Inequality in Latin America: determinants and consequences. Washington: World Bank, Policy Research Working Paper No 4504, 2008.

LÓPEZ LEVI, L. La naturaleza central de los grandes centros comerciales de la Ciudad de México. En: VILLARREAL, D. R. y MIGNOT, D. Metropolización, concentración económica y desigualdades espaciales en México y Francia. Ciudad de México: UAM, 2007, p. 107-122.

LUDEÑA, W. Lima. Ciudad y globalización. Paisajes encontrados de fin de siglo. En: ORELLANA, A. (coord.), El desafío de las áreas metropolitanas en un mundo globalizado. Barcelona: Institut d'Estudis Territorials, 2002, p. 163-191.
MARKUSEN, A. \& SCHROCK, G. The distinctive city: divergent patterns in growth, hierarchy and specialisation. Urban Studies, 2006, vol. 43, Nº 8, p. 1301-1323.

MASTER CARD. Worldwide Centers of Commerce Index. New York: Master Card, 2008. Disponible en Internet: www. mastercard.com/us/company/en/insights/ studies/2008/wcoc/index.html

MÉNDEZ, R. Transformaciones económicas y reorganización territorial en la Región Metropolitana de Madrid. EURE, 2001, No 80, p. 141-161.

MERTINS, G. y MULLER, J. El traslado de servicios de alto rango desde el centro de Bogotá hacia el norte: etapas, parámetros y consecuencias. Perspectiva Geográfica, 2000, $\mathrm{N}^{\circ} 5$, p. 103-123.

MICHALET, C.A. Mondialisation, la grande rupture. Paris: La Decouverte, 2007.

MOUHOUD, E. M. Mondialisation et delocalization des enterprises. Paris: La Découverte/Repères, 2006.

MOURA, R. y FIRKOWSKI, O. L. C. La dimensión regional de las aglomeraciones urbanas brasileñas y los retos de gestión. Pampa. Revista Interuniversitaria de Estudios Territoriales, 2007, vol. 3, № 3, p. 121-144.

NAíM, M. Ilícito. Buenos Aires, Debate, 2006.

PARNREITER, C. Ciudad de México: el camino hacia una ciudad global. EURE, 2002, No 85, p. 121-149.

PÉREZ, C. Revoluciones tecnológicas y capital financiero. La dinámica de las grandes burbujas financieras y las épocas de bonanza. México: Siglo XXI Editores, 2004.

PRZEWORSKI, A. State and the economy under capitalism. UK: Harwood Academic Publishers, 1990.

REMY, J. Ville visible, ville invisible. Un réseau aréolaire? $A+C$ - Arquitectura y Cultura, 2001, No 1, p. 144-167. 
SASSEN, S. Sociología de la globalización. Buenos Aires: Katz Editores, 2007.

SILVEIRA, M. L. Metropolis brasileñas: un análisis de los circuitos de la economía urbana. EURE, 2007, № 100, p. 149-164.

TAYLOR, P. J. World City Network. A Global Urban Analysis. London: Routledge, 2004.

TRULLEN, J. \& BOIX, R. Barcelona, polycentric metropoles and network cities. En: Barcelona, Workshop on Spatial Networks and Clusters, marzo de 2003.
UNCTAD World Investment Report 2008 : Transnational Corporations and the Infraestructure Challenge. New York: Naciones Unidas, 2008.

UN-HABITAT. The challenge of slums. Global Report on Human Settlement 2003. Londres : Earthscan, 2003.

VELTZ, P. Mondialisation, villes et territoires. L'économie d'archipel. Paris: Presses Universitaires de France, 1996.

VELTZ, P. Des lieux \& des liens. Politiques du territoire a l'heure de la mondialisation. La Tour d'Aigues: Éditions de l'Aube, 2002. 